\title{
SCANNER OBJEK TIGA DIMENSI DENGAN LASER
}

\author{
Wiedjaja $^{1}$; Suryadiputra Liawatimena ${ }^{2}$ \\ ${ }^{1,2}$ Jurusan Sistem Komputer, Fakultas Ilmu Komputer, Universitas Bina Nusantara, \\ Jln. K.H. Syahdan No.9, Palmerah, Jakarta Barat 11480 \\ suryadi@binus.edu
}

\begin{abstract}
Article present the work and fuction of a tool which is able to scan an object reconstructed into a three-dimensional object. The object could be modified by computer software. Methodology were library and laboratory research methods. From the experiment results, the scanning and reconstruction process of three-dimensional object could work well. The conclusion obtained is the optimum angle to scan the object is at an angle of $25^{\circ}$ to $35^{\circ}$. While the average time needed to play the disc is 50 seconds.
\end{abstract}

Keywords: scanner, object, three-dimensional scanning, reconstruction

\begin{abstract}
ABSTRAK
Artikel menjelaskan cara kerja dan fungsi alat yang dapat memindai sebuah objek yang bisa direkonstruksi menjadi objek tiga dimensi. Objek ini dapat dimodifikasi oleh software komputer. Metodologi yang digunakan adalah studi kepustakaan dan metode penelitian laboratorium. Dari hasil percobaan, proses pemindaian dan proses rekonstruksi objek tiga dimensi dapat berjalan dengan baik. Disimpulkan sudut optimal untuk memindai objek adalah pada sudut $25^{\circ}$ hingga $35^{\circ}$. Sedangkan waktu rata-rata yang diperlukan untuk memutar piringan adalah 50 detik.
\end{abstract}

Kata kunci: pemindai, objek, pemindaian tiga dimensi, rekonstruksi

\section{PENDAHULUAN}

Teknologi pemindaian objek ini adalah teknologi yang menggabungkan kemampuan hardware untuk memindai objek mengunakan teknik triangulasi dan software untuk mengolah data yang diterima. Sistem pemindaian objek ini akan menerima data gambar 2 dimensi yang berupa pantulan siluet sinar LASER, lalu software akan mengolah dan mengumpulkan siluet tersebut dan menjadikannya rekonstruksi objek 3 dimensi. Perancangan skripsi ini dibuat berdasarkan referensi dari beberapa website yang melakukan percobaan serupa. Dua diantaranya adalah .html dan http:// muellerr.ch/engineering/overview.html. Kedua website tersebut membuat sistem scanner objek 3 dimensi dengan memanfaatkan teknik triangulasi. Mereka juga menggunakan LASER dan webcam sebagai komponen pendukung dalam teknik triangulasi.

\section{PEMBAHASAN}

\section{Perancangan Perangkat Keras}

Perancangan perangkat keras (Gambar 1) terdiri dari 5 modul, yang terdiri dari modul webcam, modul penggerak, modul sensor, modul LASER, dan modul cermin hexagonal. Modul-modul tersebut dihubungkan dengan komputer, di mana komputer digunakan sebagai pengendali. Modul webcam terhubung dengan USB (Universal Serial Bus) port dan modul yang lainnya terhubung dengan parallel port.

\section{Modul Webcam}

Pada modul webcam diletakkan berhadapan dengan objek yang akan dipindai. Webcam yang digunakan bertipe CMOS dengan resolusi $640 \times 480$ pixel. Tipe koneksi yang digunakan adalah USB yang bisa langsung dihubungkan ke komputer. Webcam ini digunakan untuk menerima siluet yang ditimbulkan dari objek akibat pantulan sinar LASER.

\section{Modul Penggerak}

Modul penggerak (Gambar 2) digunakan untuk menggerakan piringan (platter), kemudian piringan tersebut digunakan sebagai tempat landasan untuk memutarkan objek sebanyak $360^{\circ}$. Modul penggerak terdiri dari motor stepper bipolar 2 phase, IC driver tipe L297, dan L298.

\section{Modul Sensor}

Sensor yang digunakan adalah optocoupler, yang berfungsi untuk mendeteksi apakah platter telah berputar sebanyak $360^{\circ}$. Sensor ini juga berguna dalam proses zero degree. Modul ini dihubungkan pada pin S3 yang terdapat pada parallel port (Gambar 3).

\section{Modul LASER}

Modul LASER yang digunakan berupa jenis LASER semikonduktor, yaitu LASER diode berwarna merah, dengan panjang gelombang 635 hingga $650 \mathrm{~nm}$ dan berkekuatan $1 \mathrm{~mW}$ (Gambar 6). Cahaya LASER yang masih berupa titik harus diubah menjadi berbentuk garis vertikal dengan menggunakan cermin hexagonal, yang digerakkan dengan motor. Sinar LASER harus diubah menjadi berbentuk garis agar bentuk cahayanya bisa dianalisis dan direkonstruksi oleh software. Modul LASER dihubungkan dengan pin D1 pada parallel port. 


\section{Modul Cermin Hexagonal}

Modul cermin hexagonal bekerja berdasarkan sifat pemantulan cahaya pada cermin datar, yaitu sudut cahaya datang sama dengan sudut cahaya pantul (Gambar 4). Cermin hexagonal memiliki 6 sisi cermin datar, sehingga pada saat cermin hexagonal berputar, sudut yang dipantulkan akan berubah-ubah dan akan menghasilkan garis vertikal. Modul ini dihubungkan dengan pin D0 pada parallel port.

\section{Perancangan Perangkat Lunak}

Sistem akan memindai objek menggunakan LASER. Pemindaian dilakukan dengan memutar objek sebesar $360^{\circ}$. Proses pemindaian akan menggunakan program yang berbasiskan Visual Basic. Setelah seluruh gambar tersimpan, maka akan dilakukan pemrosesan gambar oleh Matlab, kemudian gambar akan direkonstruksi menjadi bentuk objek 3 dimensi. Diagram alir program Visual Basic ditunjukkan pada Gambar 5 dan diagram alir pada program Matlab ditunjukkan pada Gambar 7.

\section{Implementasi dan Evaluasi Sistem}

Implementasi dilakukan dengan menggunakan program Matlab 7 dan sebuah program shareware VideoOCX, yang digunakan untuk mengakses webcam dan memotong file video menjadi urutan gambar diam. Sedangkan pengujian proses pemindaian menggunakan $\mathrm{PC}$ pentium IV $2,4 \mathrm{GHz}$ dan dengan RAM berukuran 512 MB dengan menggunakan sistem operasi Windows Xp Professional.

\section{Pelaksanaan/Implementasi}

Untuk memulai proses pemindaian, kita harus menentukan sudut antara webcam dengan modul LASER dan cermin Hexagonal, sehingga kita dapat menerima siluet yang menyerupai bentuk objek aslinya. Kemudian kita harus menentukan frame-rate yang akan digunakan. Selanjutnya adalah menentukan folder dan nama file yang akan disimpan pada software yang berbasis pada Visual Basic. Pada program ini akan merekam siluet objek sampai objek berputar $360^{\circ}$ dan akan mengubah hasil rekaman yang berupa file video menjadi urutan gambar. Kemudian pada program Matlab akan menganalisis urutan gambar tersebut dan merekonstruksinya menjadi gambar objek 3 dimensi.

\section{Evaluasi}

Pengujian pada pengukuran waktu motor stepper (Gambar 8) dilakukan untuk mengetahui apakah motor stepper bisa memutar landasan dengan waktu yang sama, karena jumlah gambar pada proses pemindaian sangat bergantung pada waktu yang dibutuhkan untuk memutar landasan sebesar $360^{\circ}$. Percobaan tersebut menunjukkan bahwa untuk memutar landasan sebesar $360^{\circ}$ membutuhkan waktu selama 50 detik.

Percobaan selanjutnya yaitu membandingkan pengaruh frame-rate pada webcam terhadap hasil objek 3 dimensi (Gambar 9). Pada pengujian ini ditunjukkan bahwa waktu yang dibutuhkan untuk memindai objek dengan framerate 15 FPS membutuhkan waktu rekonstruksi yang lebih lama, dibandingkan dengan pemindaian dengan frame-rate 5 FPS. Namun, pada pemindaian objek dengan frame-rate 15 FPS menghasilkan objek dengan detil permukaan yang lebih baik.

Selanjutnya adalah pengujian pengaruh sudut terhadap bentuk objek yang direkonstruksi (Tabel 1, Gambar 10 dan 11). Berdasarkan percobaan sudut yang optimal adalah sudut $25^{\circ}$ hingga $35^{\circ}$. Apabila sudut yang digunakan lebih kecil dari $35^{\circ}$, maka akan menyebabkan objek terlihat terlalu lurus. Apabila sudut digunakan lebih besar dari $35^{\circ}$, akan menyebabkan sudut membulat.

\section{PENUTUP}

Berdasarkan hasil pengujian terhadap sistem ini, dapat diambil kesimpulan sebagai berikut. Pertama, waktu ratarata yang diperlukan untuk memutar priringan sebesar $360^{\circ}$ adalah 50 detik. Kedua, penggunaan frame-rate yang lebih tinggi dapat menghasilkan gambar yang lebih detil, tetapi menyebabkan waktu rekonstruksi yang dibutuhkan menjadi lebih lama. Yang ketiga, sudut yang paling optimal untuk memindai adalah sudut $25^{\circ}$ hingga $35^{\circ}$. Apabila sudut yang digunakan lebih kecil dari $35^{\circ}$, maka akan menyebabkan objek terlihat terlalu lurus. Apabila sudut digunakan lebih besar dari $35^{\circ}$, hal ini akan menyebabkan sudut membulat.

\section{DAFTAR PUSTAKA}

Al-Housani, Mahdi. (2006). Introduction to MATLAB, 2nd Edition. http:/www.mkalhousani.com/intro2matlab.

Anonym. Industrial Circuit Application Note Stepper Motor Basics.

Anonym. Scanner 3 Dimensi. http://scriptintermedia.com/ view.php?id=726\&jenis=ITKnowledge.

Baker, Steve. (2001). A Simple 3D Scanner. http:/www. sjbaker.org/wiki/index.php?title $=$ A Simple 3D Scanner.

Gold, Ethan. (2007). Building a Homemade Laser Line Scanner.

Gonzales, Rafael C., dan Woods C. (2004). Digital Image Processing Using MATLAB. Singapore: Pearson Prentice Hall.

Laud, B.B. (1988). Laser dan Optik Nonlinear. Jakarta: Universitas Indonesia.

Lewis, Andrew. Project Splinescan. http://www.splinescan. co.uk/index.php.

Marchand, Patrick, dan Holland Thomas O. (2002). Graphics and GUIs with MATLAB, 3rd Edition. United States of America: Chapman \& Hall/CRC.

Mueller, Roger. 3D Laser Scanner. http://www.muellerr.ch/ engineering/laserscanner/default.htm.

\section{APPENDIX}

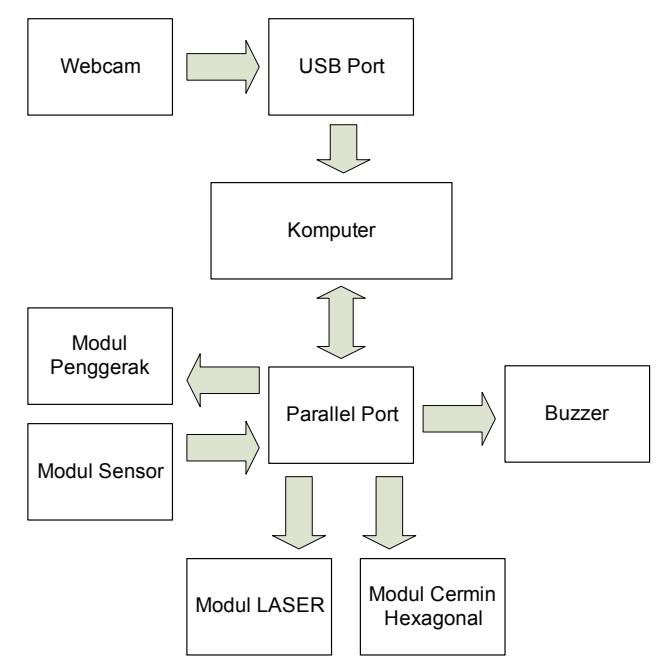

Gambar 1 Modul Perangkat Keras 

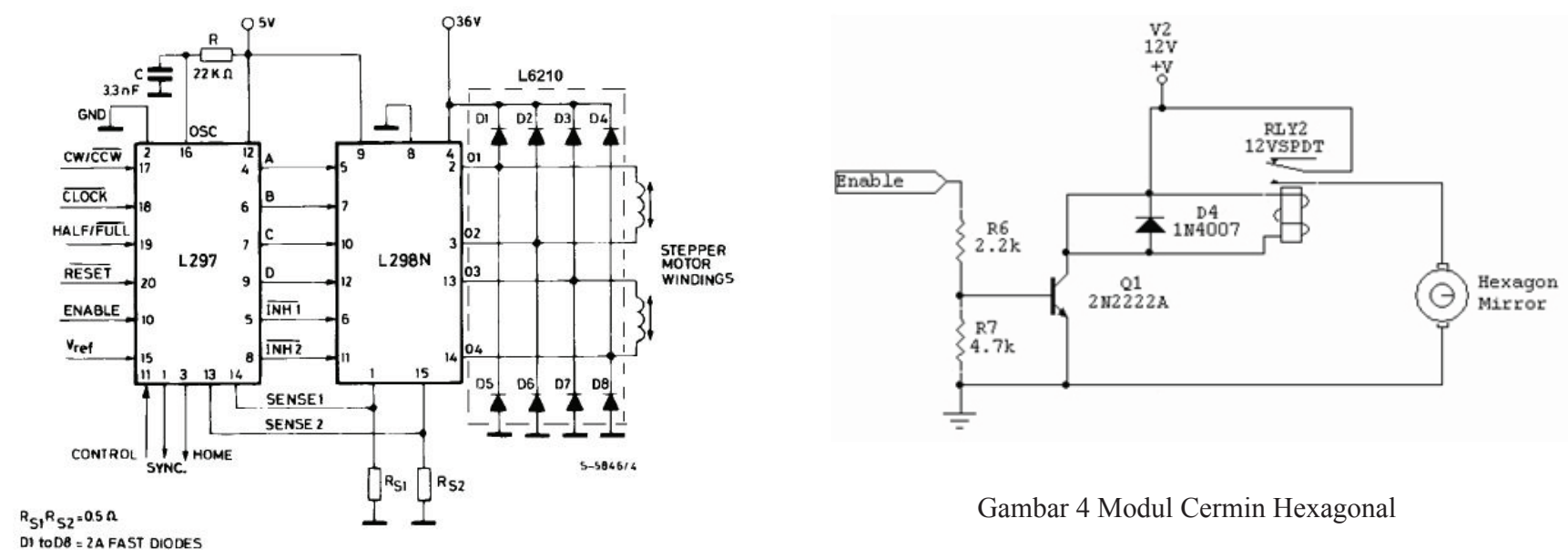

Gambar 4 Modul Cermin Hexagonal

Gambar 2 Modul Penggerak
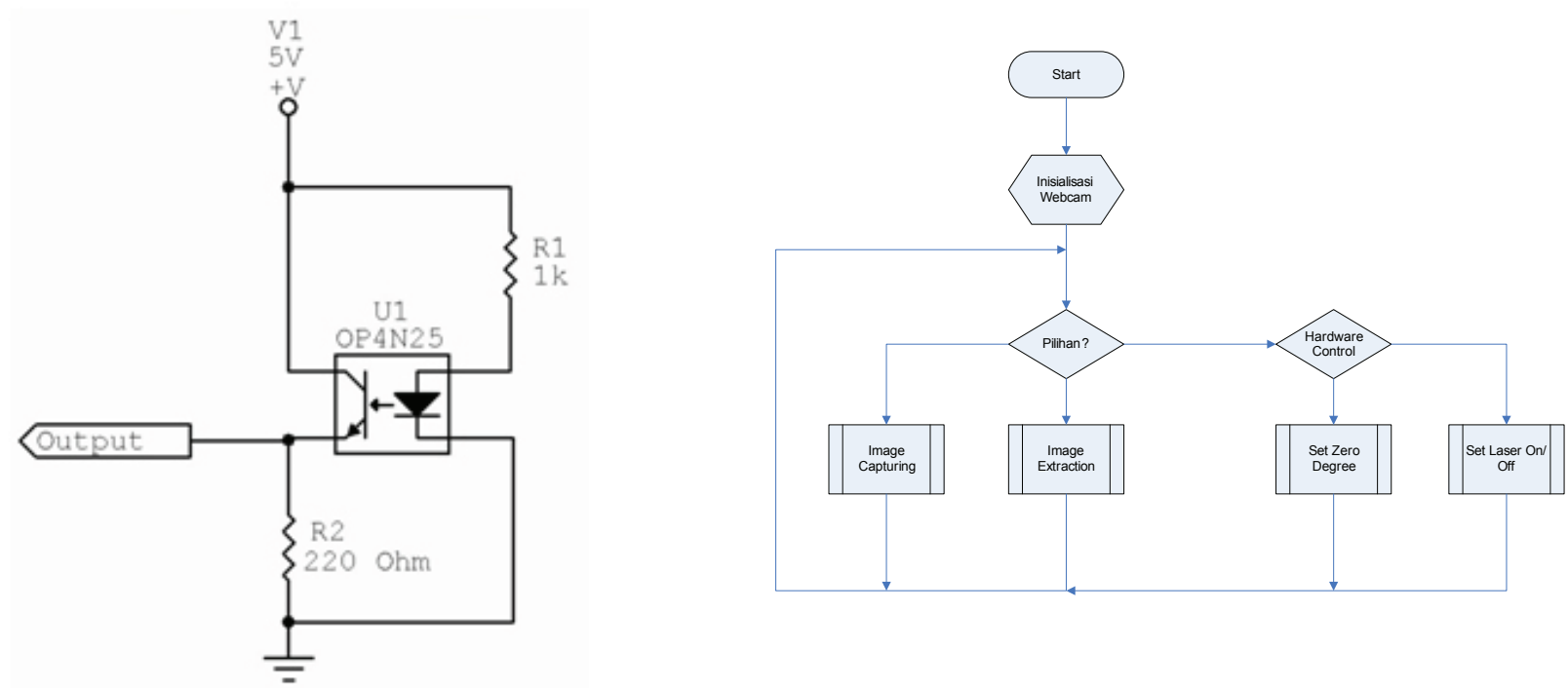

Gambar 3 Modul Sensor

Gambar 5 Diagram Alir Program Visual Basic

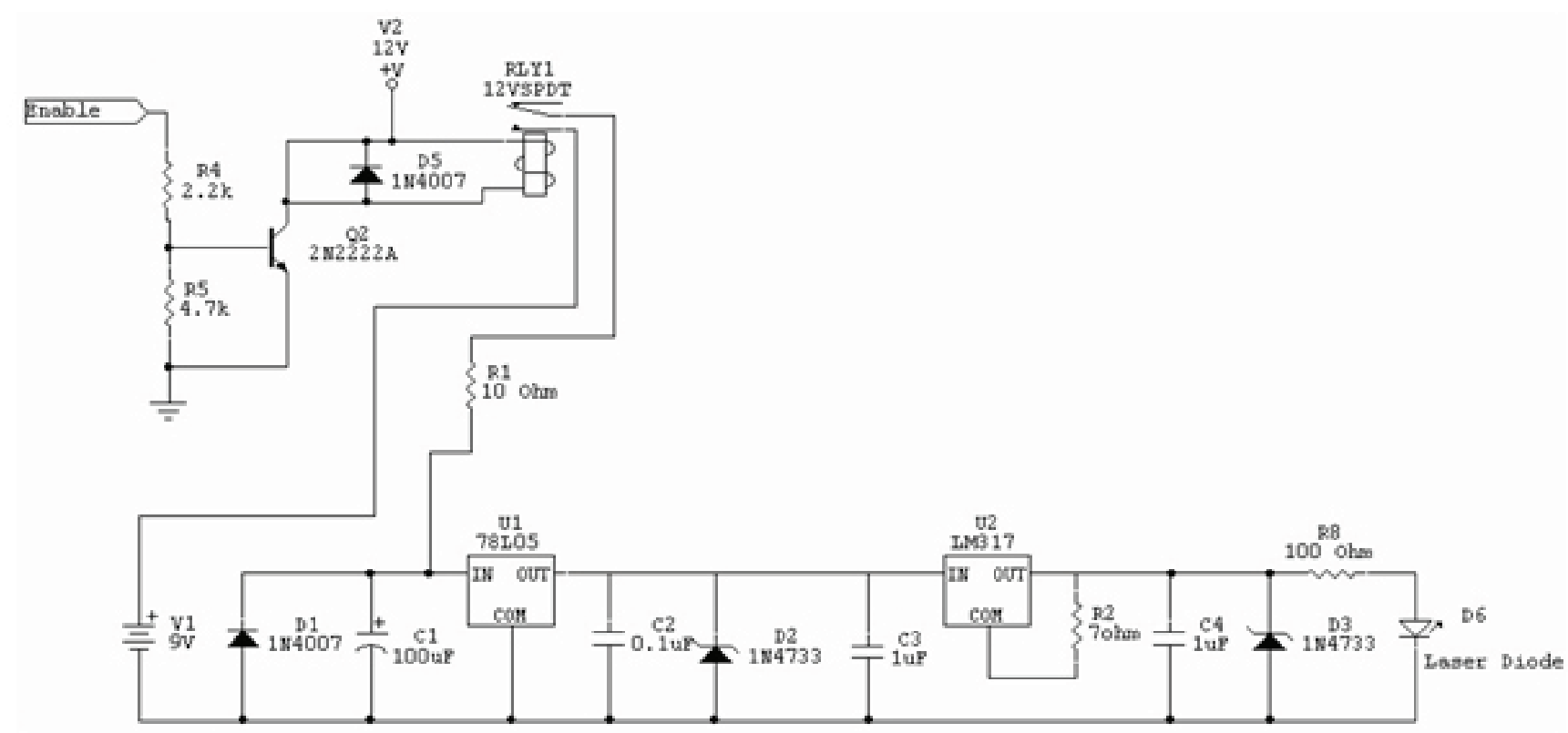

Gambar 6 Modul LASER 


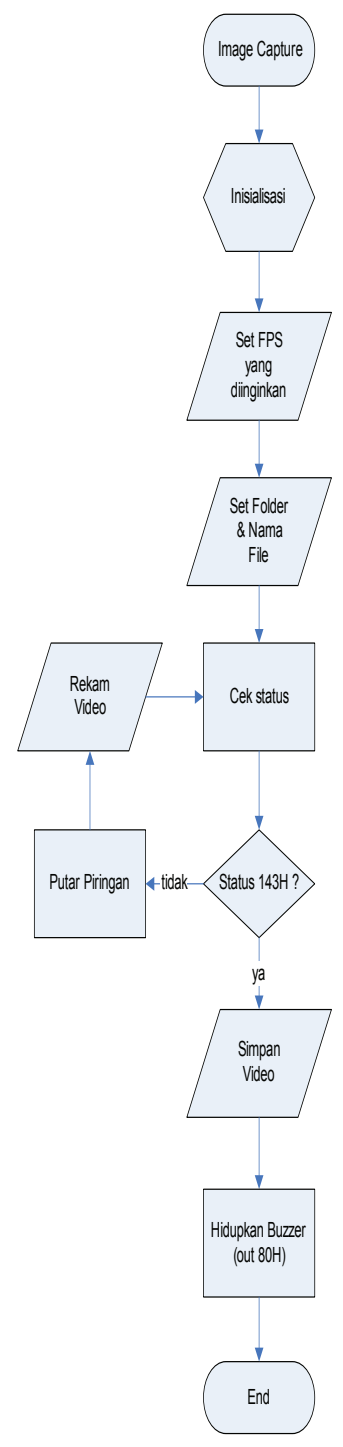

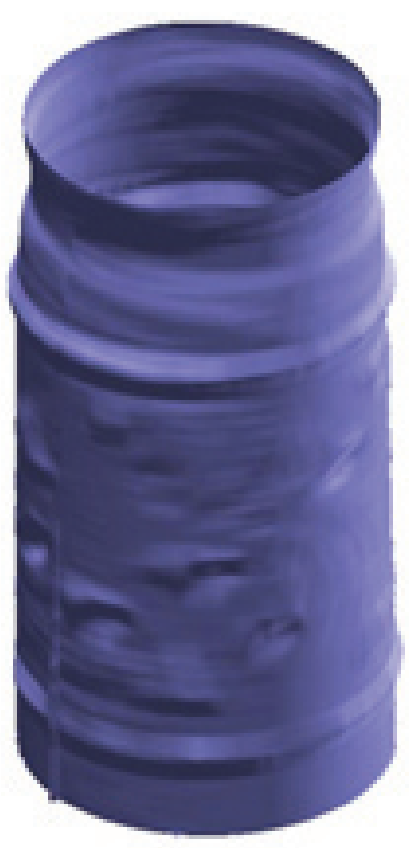

A

Frame-rate 5 FPS

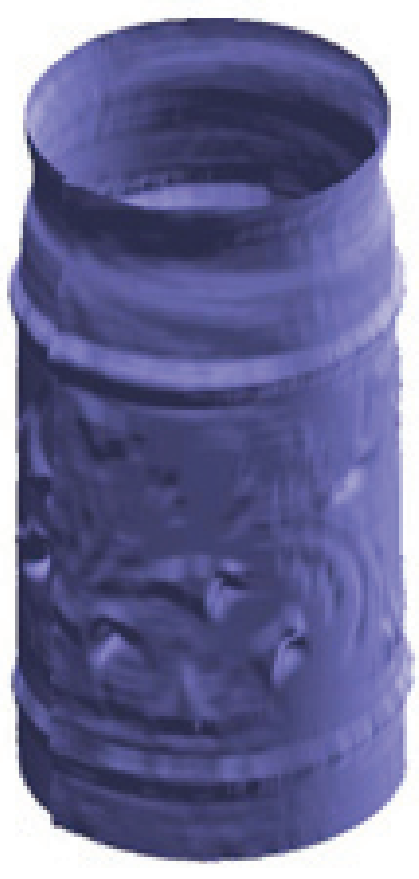

B

Frame-rate 15 FPS

Gambar 9 Objek Tempat Alat Tulis pada Sudut $20^{\circ}$

Gambar 7 Diagram Alir pada Program Matlab

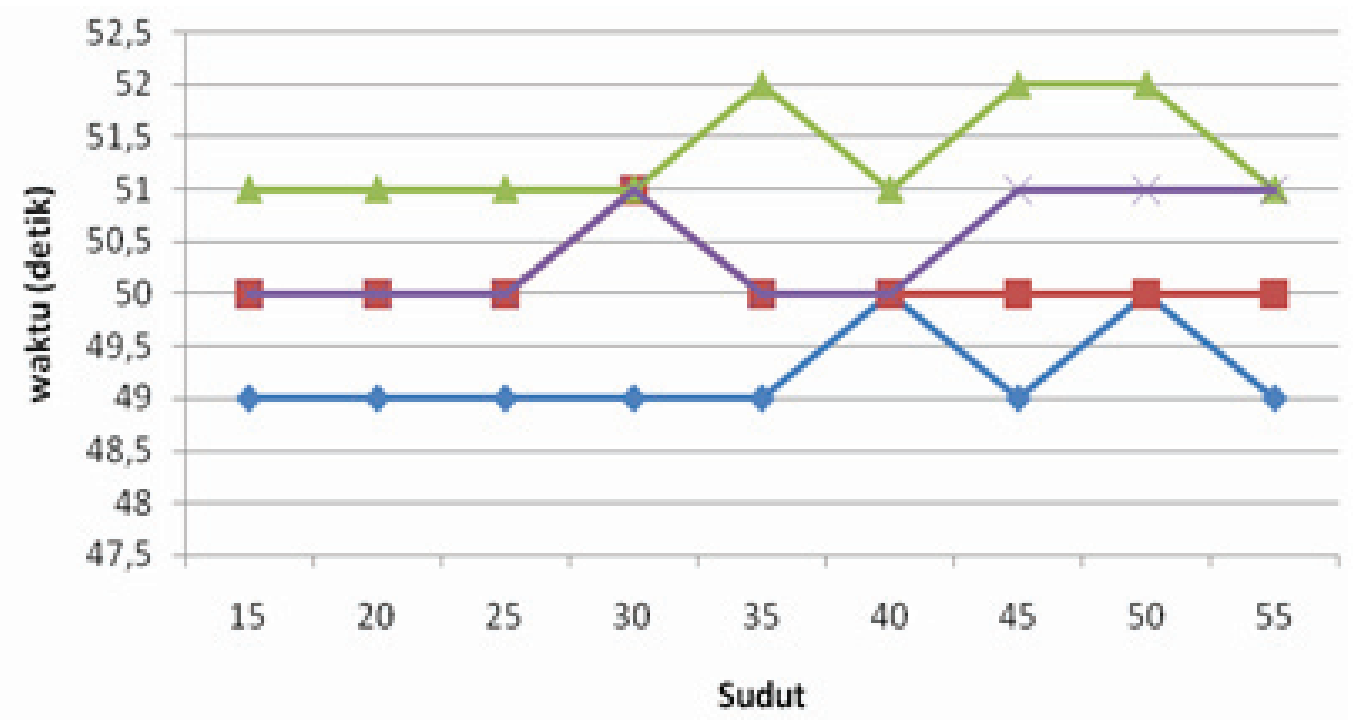

$\leftrightarrow$ Gucci $\rightarrow$ Botol bedak bayi $\rightarrow$ Tempat alat tulis $\longrightarrow$ Boneka bebek 


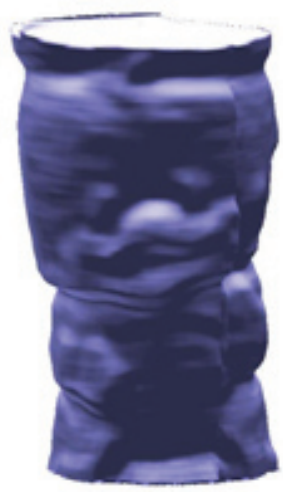

( a )

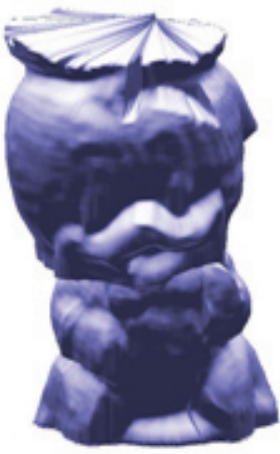

( b )

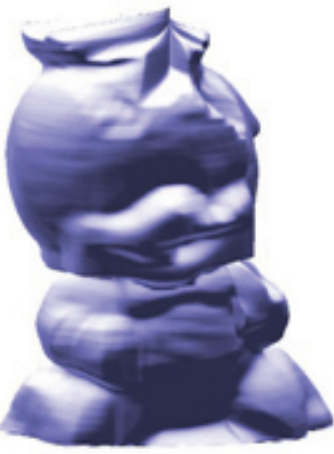

(c)

Boneka Bebek dengan Sudut $15^{\circ}$ Boneka Bebek dengan Sudut $35^{\circ}$ Boneka Bebek dengan Sudut $50^{\circ}$ Gambar 10 Objek Rekonstruksi dari Boneka Bebek

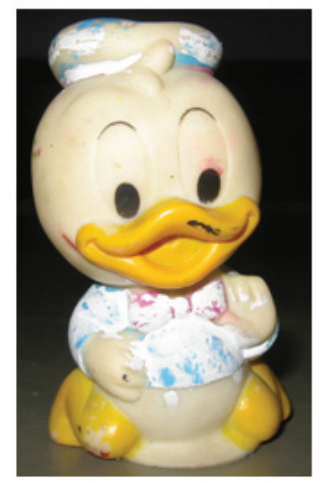

Gambar 11 Objek Boneka Bebek

Tabel 1 Waktu Rekonstruksi dan Jumlah Gambar yang Dihasilkan pada Objek Guci

\begin{tabular}{|c|c|c|c|c|c|c|}
\hline Nama & Bahan & Warna & $\begin{array}{c}\text { Sudut } \\
\text { (derajat) }\end{array}$ & Fps & $\begin{array}{l}\text { Jumlah } \\
\text { Gambar }\end{array}$ & $\begin{array}{l}\text { t Rekonstruksi } \\
\text { (menit'detik) }\end{array}$ \\
\hline \multirow{18}{*}{ Guci } & \multirow{18}{*}{ Keramik } & \multirow{18}{*}{ Merah } & 15 & 5 & 249 & 22 \\
\hline & & & 20 & 5 & 249 & 19 \\
\hline & & & 25 & 5 & 249 & 19 \\
\hline & & & 30 & 5 & 249 & 16 \\
\hline & & & 35 & 5 & 247 & 16 \\
\hline & & & 40 & 5 & 248 & 25 \\
\hline & & & 45 & 5 & 249 & 20 \\
\hline & & & 50 & 5 & 249 & 23 \\
\hline & & & 55 & 5 & 248 & 23 \\
\hline & & & 15 & 15 & 747 & 56 \\
\hline & & & 20 & 15 & 745 & 55 \\
\hline & & & 25 & 15 & 744 & 56 \\
\hline & & & 30 & 15 & 744 & 55 \\
\hline & & & 35 & 15 & 754 & 56 \\
\hline & & & 40 & 15 & 755 & 1'14 \\
\hline & & & 45 & 15 & 752 & 1'06 \\
\hline & & & 50 & 15 & 750 & $1 ' 06$ \\
\hline & & & 55 & 15 & 754 & $1^{\prime} 08$ \\
\hline
\end{tabular}

